\title{
ARMANDA ÁLVARO ALBERTO: ESCOLA NOVA E REPRESSÃO POLÍTICA NOS ANOS 1930
}

\author{
José Damiro de Moraes ${ }^{1}$ \\ Universidade Federal do Estado do Rio de Janeiro (UNIRIO)
}

\section{RESUMO}

A trajetória da signatária do Manifesto dos Pioneiros de 1932, Armanda Álvaro Alberto revela sua atuação no campo educacional e político dos anos 1930. Poucos estudos têm relacionado o escolanovismo com os conturbados anos 1930 e a repressão política. Ao criar a Escola Regional em Meriti, Armanda Álvaro Alberto iniciou um projeto inovador no campo educacional no Brasil. Entretanto, ao ampliar sua participação no meio político em defesa dos direitos das mulheres entrou em choque com o governo Vargas resultando em sua prisão. $\mathrm{O}$ estudo e análise dos documentos seguiram uma perspectiva dialética considerando questões sócio-políticas do período. O artigo procura mostrar a relação de Armanda Álberto Alberto como os embates ideológicos do período e sua coerência em acreditar em uma nova sociedade com uma educação que atendesse as camadas populares. Palavras-chave: Escola Nova; Armanda Álvaro Alberto; Repressão Política

\section{ALBERTO ALVARO ARMANDA: NEW SCHOOL AND POLITICAL REPRESSION IN THE YEARS 1930'S}

\section{ABSTRACT}

The trajectory of the signatory of the Manifest of the Pioneers, 1932, Armanda Álvaro Alberto reveals its role in education and politics in the 1930's. Few studies have related escolanovismo with the troubled 1930's and political repression. When creating the Regional School in Meriti, Armanda Álvaro Alberto started an innovative project in the educational field in Brazil. Nevertheless, to expand its participation in the political means to defend the rights of women clashed with the Vargas government resulting in his arrest. The study and analysis of documents followed a dialectical perspective considering sociopolitical issues of the period. The article attempts to show the relationship of Armanda Álvaro Alberto as ideological confrontations of the period and its consistency in believing in a new society with an education that meets the lower classes.

Keywords: New School; Armanda Álvaro Alberto; Political Repression

\section{Introdução: Da escola proletária à escola de regional de Meriti}

Armanda Álvaro Alberto nasceu em 10 de junho de 1892 no Rio de Janeiro e faleceu na mesma cidade em 5 de fevereiro de 1974. Era filha de Álvaro Alberto da Silva e Maria Teixeira Motta e Silva. Estudou em casa com professores particulares e frequentou alguns cursos no Colégio Jacobina entre 1912-1914, onde também iniciou carreira de professora em 1917 (MIGNOT, 2002). Beatriz Osório, normalista que visitou a escola no anos 1940, descreveu Armanda: "como educadora é assombrosa. No entanto, nunca cursou uma escola normal” (OSÓRIO, 1944). 
Essa educadora iniciou sua experiência educacional em Angra dos Reis (RJ) denominada de Escola Proletária. Na localidade não era oferecida educação formal, fosse em escola pública fosse em escola privada. Assim, ao registrar sobre esse começo Armanda, revelou que sua escola "funcionou regularmente de maio a outubro de 1919, ao ar livre, à sombra dos bambus. Uma mesa de pinho, uma cadeira e esteiras pelo chão - eis o mobiliário. Cerca de 50 alunos - desde 3 até 16 anos. Foram divididos em turmas" (ALBERTO, 1932B). Entretanto, a iniciativa não continuou pois o seu irmão Álvaro Alberto foi transferido por ordem da Marinha e ela obrigada a abandonar o projeto temporariamente.

Ao voltar para a cidade do Rio de Janeiro, Armanda Alberto empenhou-se em novos contatos para retomar o projeto da Escola Proletária. Assim, conseguiu apoio da firma F. Venâncio \& Cia, fabricante dos explosivos Rupturita em Meriti ${ }^{2}$ (ALBERTO, 1968, p. 40) para desenvolver suas ideias, atendendo aos filhos dos empregados e à comunidade próxima da fábrica.

A existência dessa empresa não pode deixar de ser mencionada, pois foi de onde originou-se parte do financiamento da Escola de Armanda. Segundo Beatriz Osório, "os operários da fábrica se queixavam da falta de escola para seus filhos" (OSÓRIO, 1944). Esse fato motivou Armanda Alberto a retomar o projeto educacional que fora interrompido em Angra dos Reis.

Em 1921, criou a Escola Proletária de Meriti, localizada no meio rural, ainda que nas proximidades do Rio de Janeiro ${ }^{3}$ (RJ). Logo alterado para Escola Regional de Meriti, espaço notabilizado pelo ineditismo de algumas ações e citada como referência por alguns escolanovistas. Ao lado da escola foi organizada uma biblioteca aberta à comunidade com a designação de Euclides da Cunha ${ }^{4}$, considerada uma iniciativa pioneira na região. Outras duas novidades fizeram parte do cotidiano da escola de Armanda: o Círculo de Mães, com a finalidade de realizar a integração com a comunidade, e a criação da merenda escolar (MIGNOT, 2002), ação que apelidou a escola de "Mate com angu".

A preocupação por melhores condições educacionais no Brasil levou Armanda à presidência da Liga Brasileira Contra o Analfabetismo em 1923 e à participação na criação da Associação Brasileira de Educação (ABE) em 1924. Além disso, na Primeira Conferência Nacional de Educação, realizada em 1927 na cidade de Curitiba, a Escola Regional de Meriti recebeu aprovação por voto de aplauso. Assim, essa educadora tornouse uma defensora de um modelo regional de educação que para ela deveria unir a iniciativa pública com a particular. Posteriormente, sua tese sobre o regionalismo foi aprovada na III Conferência Nacional de Educação em 1929 da ABE, realizada em São Paulo. Esse fato coloca em evidência a sua proposta inovadora de escola regional o que lhe garantiu uma projeção no campo educacional brasileiro e a participação como signatária no Manifesto dos Pioneiros de 1932.

Com caráter modernizador, a escola recebeu apoio de vários educadores e simpatizantes que assinam as listas de presenças nas reuniões anuais ou eram apenas citados como colaboradores em agradecimentos proferidos por Armanda. Encontramos os nomes de Belisário Pena, Francisco Venâncio Filho, Heitor Lyra da Silva, Roquette Pinto, sua mãe Maria T. da Motta e Silva (viúva Álvaro Alberto), Celso Kelly, Paschoal Leme, Edgar Süssekind de Mendonça (marido de Armanda Álvaro Alberto), entre outros.

Ainda nas Atas da Escola Regional de Meriti chamamos a atenção para a presença do irmão de Edgar, Carlos Süssekind de Mendonça, e de Maria Lacerda de Moura, presentes em algumas das Assembleias Gerais de sócios da Fundação Álvaro Alberto, 
entidade criada para gerir a instituição. $O$ fato merece relevo porque essas duas personalidades eram ligadas ao pensamento anticlerical e antifascista, sem esquecer da aproximação de Maria Lacerda com o anarquismo. Esse dado oferece pistas da trajetória de Armanda nesses anos que antecederam o Estado Novo e ajudam a problematizar sua atuação no campo político do período.

A partir da promulgação do Estado Novo, Armanda afastou-se da política e retornou à fomentação da proposta pedagógica na Escola Regional de Meriti. A escola assumia cada vez mais um projeto renovador, visto que se caracterizava pela ausência de adoção de notas, prêmios ou castigos e que preconizava os seguintes princípios, resumidos em quatro cartazes com os dizeres em azul: Saúde, Alegria, Trabalho e Solidariedade.

Essa unidade educacional tornou-se referência para vários intelectuais como Lourenço Filho, que a considerava como a "mais completa experiência de educação renovada pela intenção socializadora, os procedimentos didáticos e a compreensão de cooperação da família na obra da escola" (LOURENÇO FILHO, 1978, p. 176). Por sua vez, Fernando de Azevedo, em A Cultura Brasileira, citou a Escola de Armanda como uma "das primeiras e de sentido mais corajosamente renovador" (AZEVEDO, 1996, p. $633)$.

O teor escolanovista, destacado por Lourenço Filho (1978), aparece nas relações cotidianas vividas dentro desse espaço pedagógico. Ao defender seu modelo de Escola Regional, a educadora também elegia os conteúdos que deveriam estar presentes no desenvolvimento curricular:

linguagem, desenho (fazem parte de todas as aulas), cálculo, geometria, trabalhos manuais femininos e masculino, jogos e cânticos infantis, estudos da natureza, higiene, jardinagem e criação, geografia (especialmente do Brasil), história da humanidade (especialmente do povo brasileiro), economia e trabalhos domésticos (ALBERTO, 1968, p. 39).

O programa do curso completo da Escola Regional estava dividido em quatro graus, dispostos em três fundamentais e um de aperfeiçoamento em desenho, trabalhos manuais, economia doméstica, jardinagem e criação. Essa organização não se utilizou dos testes psicológicos, tradicionais daquele momento. Para Edgard Süssekind Mendonça, marido de Armanda Alberto, a pobreza "característica regional mais considerável da povoação em que ensinamos, invalida a regra clássica de Binet, que ordena classificar cada aluno em sua idade mental" (MENDONÇA, 1968, p. 17). Com essa afirmação, negava a Psicologia como suporte para classificar, avaliar e disciplinar as crianças da escola. Em uma comunidade afastada do grande centro urbano, a contribuição da Psicologia em voga seria muito pequena perante as dificuldades sociais impostas à população, vítima de imensas desigualdades de toda ordem.

Conforme Julia Lopes de Almeida, as aulas ocorriam ao ar livre "quando o bom Deus permite sol clemente e dias secos" e, na impossibilidade, "em uma casa de campo modestíssima, rodeada de árvores ainda novas, plantadas a pedido da diretora". No interior do estabelecimento, "salas de telhas vãs", as paredes a cal sustentavam retratos de alguns escritores nacionais. Em uma dessas salas, havia uma biblioteca com seus livros encapados de "papel de uma só cor" (ALMEIDA, 1968, p. 60).

Percorrendo os cômodos, uma das salinhas abrigava o Museu Regional. Nesse espaço, eram recolhidas as coleções que contavam com a contribuição de todas as crianças: 
pedrinhas, ovo de passarinho, inseto, ou "qualquer coisa que lhes pareça [...] original e digno de atenção". Armanda, sorridente, recebia "as dádivas" e estudava-as com as crianças. Didaticamente, esses elementos eram classificados de acordo com qualidade e espécie. Assim, incentivava a "criançada a estudar a natureza e amar, nas suas expressões mais variadas, todos os prodígios da criação" (ALMEIDA, 1968, p. 60). Dessa maneira, a educadora concretizava uma das características da Escola Nova - a prática deveria preceder a teoria (LOURENÇO FILHO, 1978, p. 163).

O método de ensino na Escola Regional adotava como diretriz a não interrupção das atividades interessantes durante o tempo em que os alunos nelas estivessem envolvidos (ALBERTO, 1968, p. 37-38). Essa diretriz chamou a atenção da visita de Yvonne Jean que, ao se referir a essa questão em 1948, assim ponderava

O princípio é excelente, mas só pode ser posto em prática por professoras experimentadas. Uma única pessoa não pode cuidar de diversas turmas. As professoras que ajudam a Diretora são cheia de boa vontade, mas seu preparo não dá margem a iniciativas pessoais desenvolvidas. O princípio de liberdade que rege as aulas traz consigo um perigo: o de seguir os desejos dos alunos que, naturalmente, interessam-se particularmente pelas matérias mais fáceis ou agradáveis, em vez de orientá-los para que assimilem os ensinamentos mais áridos (JEAN, 1968, p. 147).

Armanda Alberto sustentou essa diretriz metodológica durante sua permanência frente a escola. Nesse sentido, na prática educativa, as crianças pequenas eram atendidas com exercícios fundamentados na pedagogia de Maria Montessori. Os recursos pedagógicos provinham da própria natureza - conchas, pedrinhas, folhas, frutos, retalhos de fazendas diversas, fitas. As atividades começavam logo pela manhã, entre seis e sete horas. Posteriormente, esse horário sofreu alteração e passou a ser das 10 às 15 horas (ALBERTO, 1932A).

Não podemos nos esquecer de que, devido a sua localização no meio rural, em uma região afastada e pobre, o trabalho educacional assumiu, muitas vezes, características de assistência social. Dessa forma, distribuíam-se remédios por meio do Dr. Francisco Venâncio Filho, que os obtinha na Saúde Pública. Também os alunos recebiam material escolar - cadernos, lápis - doados pelo comandante Álvaro Alberto (ALBERTO, 1932A).

A já citada Biblioteca Euclides da Cunha que tinha como objetivo atender a alunos, professores e moradores, dividia-se em três seções. No ano de 1932, Armanda Alberto informava que o acervo possuía 715 volumes. Mais adiante, em setembro de 1944, a normalista Beatriz Osório, durante sua visita, contabilizou cerca de mil exemplares no acervo. Além disso, suas anotações davam ênfase à organização do Museu Regional, pois "é interessantíssimo e mais bem dotado que o de muito estabelecimento importante", exibindo coleções de animais empalhados, de couro e peles, ninhos, fósseis, sementes, minerais, objetos de outras regiões do Brasil (OSÓRIO, 1944).

Se em sua origem, a escola de Armanda preconizava não seguir nenhum modelo, nenhum programa escrito, mais tarde a professora admitiu que os fundamentos da ação pedagógica foram buscados em Montessori. Mas, em tese apresentada na $1^{\text {a }}$ Conferência da ABE (1927), revelava que "é preciso confessar aqui, com franqueza, que tivemos de modificar, ou mesmo de desistir de muitas coisas praticadas com sucesso nos meios estrangeiros" (ALBERTO, 1968, p. 38). E, ao concluir a tese, defendia o princípio da 
liberdade e o trabalho como base dos métodos de preparação dos professores e da educação,

venham eles da Suíça, dos Estados Unidos, da Itália, desde que se baseiem na liberdade, que consente a plena expansão da individualidade, e no trabalho, que leva a criança a observar, a experimentar, a descobrir e o fazer por si - são os únicos dignos de serem adotados hoje em dia. Em nosso meio, poucos são os professores capazes de os empregar com segurança; faz-se necessário, portanto, antes de tentar a escola ativa, preparar os mestres para ela (ALBERTO, 1968, p. 41, grifo nosso).

Sua preocupação recaía sobre a formação dos docentes, ou seja, em sua visão era necessário a preparação dos professores dentro dos métodos e não apenas "importar" teorias para criar novas práticas educacionais.

\section{De professora à rebelde comunista}

Em relatório da Delegacia Especial de Segurança Política e Social (DESPS) de 1943, com o objetivo de realizar um "balanço" das atividades da delegacia e justificar o desempenho de cada setor, referia-se ao trabalho realizado pelo serviço secreto: "infiltrados em todas as camadas sociais desta Capital, o SERVIÇO SECRETO vem cooperando com grande êxito para o mais perfeito trabalho de infiltração mantido pela seção de Segurança Social". Isso só era possível, continua o Relatório, dada a situação dos "agentes que constituem o corpo do Serviço que empresta o título ao presente capítulo, são estranhos aos trabalhos da Polícia Civil do Distrito Federal e estão constantemente em contato com o seu meio próprio, donde, aliás foram recrutados" (RELATÓRIO, 1944, p. 46). A exposição da DESPS mostra que no seio de entidades como a Aliança Nacional Libertadora (ANL) e a União Feminina do Brasil (UFB) estavam os olhos vigilantes da repressão.

A participação de Armanda como presidente da UFB, entidade filiada a ANL, levou a DESPS a acompanhar seus passos e ações até mesmo após o fechamento dessas entidades. Sobre a Aliança, as investigações revelavam que era

organizada clandestinamente na sede do sindicato dos Bancários, a qual registrou solenemente como sociedade civil - sem, contudo, divulgar os seus estatutos, regendo pelo livre arbítrio dos seus diretórios, constituído de civis e militares que, embora suspeitados pelas suas atividades dúbias, gozavam de certas prerrogativas, supondo-se, assim a coberto das vistas policiais (RELATÓRIO, 1944, p. 36-37, grifo nosso).

É legítimo afirmar que o documento produzido pela DESPS visava criminalizar qualquer atividade democrática e participativa, por simples que fosse, da ANL. Além de produzir uma justificativa para as prisões e perseguições que visavam desarticular a oposição e qualquer movimento revolucionário. Ao analisar o Estatuto "desconhecido" pela Delegacia encontramos uma entidade de base representativa e federada, como explicitado nos seguintes artigos 
Artigo $11^{\circ}$ - Os Diretórios dos Estados são eleitos anualmente, por assembleia geral dos associados da capital e dos Estados.

Parágrafo $1^{\circ}$ - No caso de se constituírem Diretórios Municipais será proporcional ao número de aderentes em cada Município.

Artigo $12^{\circ}$ - Os Diretórios Municipais e o Diretório do Distrito Federal serão eleitos por assembleia geral de aderentes, na sede do Município.

[...]

Parágrafo $3^{\circ}$ - Cada núcleo elegerá um Secretariado composto de três ou cinco membros, para dirigir seus trabalhos. (ALIANÇA NACIONAL LIBERTADORA, 1935, grifos nossos).

Assim, da mesma forma que a Aliança foi espreitada pelo DESPS, a União Feminina do Brasil teve igual tratamento, sendo exposta como entidade "intimamente ligada à ANL, cuja periculosidade logo se constatou, tão suspeita eram as intelectuais escolhidas e aclamadas para dirigi-las" (RELATÓRIO, 1944, p. 37). A educadora Armanda, na condição de presidente da UFB, rotulada como uma perigosa intelectual e recebeu especial atenção da polícia política de Getúlio Vargas.

Nesse momento, ao radicalizar seu discurso, a ANL ficou mais exposta e em rota de colisão com os objetivos do governo de Getúlio Vargas. Esse cenário redundou na edição da Lei ${ }^{\circ}$ 38, também conhecida como Lei de Segurança Nacional ou como foi chamada pelo militantes de esquerda: "Lei Monstro", de 4 de abril de 1935. Nela foram definidos os "crimes contra a ordem política e social" e deliberava, já em seu primeiro artigo, que: "tentar diretamente e por fato, mudar, por meios violentos, a Constituição da República, no todo ou em parte, ou a forma de governo por ela estabelecida [...]", seria considerado crime, sendo que a pena variava de "reclusão por seis a dez anos aos cabeças e por cinco a oito aos corréus".

A Lei de Segurança Nacional determinava também penas de seis meses a dois anos de prisão às ações como "incitar diretamente o ódio entre classes sociais" ou "instigar as classes sociais à luta pela violência". Finalmente, o golpe fatal para a existência de entidades como a ANL estava no art. 29, que versava sobre o caráter das atividades das organizações que, se enquadradas como subversivas da ordem política ou social, seriam fechadas pelo governo.

A situação interna da Aliança também foi tomando outra direção, empurrando a entidade para a disputa pelo poder institucional. Esse era o objetivo discutido e aprovado pelo Plenum do Comitê Central (CC) do PCB, em maio de 1935. Nessa reunião, o CC identificava a ANL como um "verdadeiro instrumento da tomada ao poder e para isso tem que mobilizar as grandes massas para levá-las para o Governo Popular Nacional Revolucionário, derrubar Getúlio e seu governo" (VIANNA, 1995, p. 49).

O discurso de Luis Carlos Prestes em 5 de julho de 1935 que conclamava a tomada do poder pela ANL, incitou a rápida resposta do governo Vargas. A reação veio com o Decreto $\mathrm{n}^{\circ} 229$ de 11 de julho de 1935 em que determinava o fechamento dessa organização e de seus núcleos em todo o território brasileiro.

A repressão alastrou-se e não poupou a UFB, entidade que havia declarado publicamente apoio à Aliança. Assim, as atividades da organização foram cessadas pelo mesmo decreto que fechou a ANL.

Todavia, permaneceu a dúvida sobre a extensão deste decreto em relação à UFB. Getúlio Vargas e Vicente Rao ${ }^{5}$ (ministro da Justiça) lançaram mão de mais uma publicação 
no Diário Oficial, o Decreto $\mathrm{n}^{\circ} 246$ de 19 de julho de 1935. Nesse, a UFB era enquadrada também como sociedade que realizaria "atividade subversiva da ordem política e social, ordenando o fechamento dos seus núcleos em todo o território nacional".

Essa avaliação era reforçada pelos documentos da DESPS e, provavelmente, ajudaram na decisão de fechar a UFB pois, além de ser considerada "subversiva", era filiada a uma entidade já caçada.

As investigações da DESPS apontavam para a assembleia de adesão da UFB à ANL - proclamada e aceita de forma (quase) unânime pelas sócias - "contrariando, assim, um dos seus princípios estabelecidos no manifesto programa em que diz que não é uma organização política nem está ligada a nenhum partido político" (grifo no original). Segundo o entendimento da Delegacia, a Aliança era, na verdade, um partido político extremista.

Na citada assembleia, uma única associada se manifestou contrária a tal adesão foi a professora Abigail, do Colégio Anglo Brasileiro, que achava precoce a filiação a uma organização que "segundo ouviu dizer era comunista". A posição assumida professora causou protestos e apartes de quase toda a assistência. Segundo esse documento da DESPS, os discursos das mulheres presentes enfatizavam a necessidade da UFB sair do campo teórico, avançando para a ação efetiva, o que significava, nas palavras de Beatriz Bandeira

Lutar pelos direitos populares pela própria dignidade humana e particularmente pelos direitos da mulher na sociedade, significa lutar contra o fascismo que na sua denominação brasileira de "integralismo" é a expressão da brutalidade requintada, da negação de todos os direitos do homem e a destruição de todas as conquistas femininas (DOSSIÊ 5 UFB grifos no original).

A situação de ilegalidade e o enquadramento da ANL e da UFB na Lei de Segurança Nacional e no Decreto $n^{\circ} 246$ não impediram a realização de uma importante reunião de 31 de outubro de 1935.

A reunião, que ocorreu na sede da entidade Oposições Coligadas, também foi acompanhada por agente do DESPS e registrada no Dossiê 5. Nesse documento, relata-se que o encontro chamado publicamente de "Comitê de Propaganda e Luta Contra a Guerra", ocultando a verdadeira finalidade de reunir as sócias da UFB. Entre as mulheres presentes, destacaram-se Armanda Álvaro Alberto e Maria Lacerda de Moura. Nessa ocasião a UFB recebeu apoio de sindicatos e associações operárias, que "hipotecavam solidariedade" à entidade perseguida pelo governo (DOSSIÊ 5 - UFB).

$\mathrm{O}$ registro das discussões efetuadas na reunião explicita as críticas à guerra, ao fascismo e ao imperialismo. Entretanto, tudo indica que o ponto alto do encontro foi a formação de um comitê de 16 mulheres, composto por "uma representante operária, uma doméstica e outra dos bairros, destacando os nomes de Rachel Prado, Eugênia Herman, Maria Lacerda de Moura, Italia Fausta, Armanda Álvaro Alberto, Ivete Ribeiro, Lídia Freitas, Laudinia Trotta, Nise da Silveira, Eugênia Álvaro Moreira, Maria Ignez Coutinho Ferrreira, Maria Wercook de Castro" (DOSSIÊ 5 - UFB). O importante comitê tinha como meta recuperar a condição legal da entidade.

As investigações da DESPS indicaram que o objetivo da UFB era o análogo ao da ANL: "pelo que acabamos de ver, provado está que a União Feminina do Brasil se regia pelos mesmos princípios da ANL e dos demais partidos de fins extremistas". 
$\mathrm{Na}$ luta pela legalidade, o advogado Heitor Lima impetrou um mandado de segurança com o número 127, buscando manter a continuidade dos trabalhos da UFB. Valendo-se dos artigos da Constituição Federal que defendiam a liberdade de pensamento e o direito à associação, o advogado organizou a defesa. Ao anexar recortes de jornais, utilizou o argumento de que a entidade feminista não se havia filiado à ANL, mas sim declarado apoio à sua luta contra o integralismo. Por fim, questionava a ação do governo que, na interpretação acerca do caráter da UFB, julgava-a como subversiva a partir da Lei de Segurança Nacional.

Como anexo ao mandado de segurança, o advogado Heitor Lima juntou alguns documentos, entre os quais o Manifesto Programa da UFB, no qual a associação define-se: "[...] não é uma organização política, nem está ligada a nenhum partido político, mas defenderá em seu programa direitos econômicos, sociais e políticos da mulher" (UNIÃO FEMININA DO BRASIL, 1935). A condução do debate culminou com a denegação do mandado de forma unânime pelo Supremo Tribunal em 23 de setembro de 1935, fato que impediu o retorno das atividades da UFB.

Em novembro de 1935 eclodiu o movimento insurrecional denominado pelos seus críticos de Intentona Comunista. Os acontecimentos que se seguiram foram marcados pelo acirramento de posições nacionalistas e pela ação dos órgãos repressivos, levando militantes e simpatizantes da ANL à prisão nos anos seguintes. Entre os presos, várias mulheres. Entre estas, figurava o nome de Armanda Álvaro Alberto, diretora da Escola Regional de Meriti, suspeita de participar do levante comunista.

Nesse momento o Congresso Nacional colaborou com a repressão prorrogando por quatro vezes sucessivas (cada uma por um período de 90 dias) a vigência do Estado de Sítio a partir de 1935. A repressão tornava-se mais sofisticada e foi criada a Comissão Nacional de Repressão ao Comunismo com poderes em todo o território nacional, inclusive o de "propor a prisão de qualquer pessoa cuja atividade pudesse ser considerada prejudicial às instituições" (KELLER, 2001).

O ano de 1936 teve como marca a repressão e a caça aos ditos "comunistas" (denominação abrangente para trotskistas, socialistas e anarquistas, simpatizantes ou não da Aliança), envolvidos direta ou indiretamente na tentativa de golpe de Estado. Com o objetivo de cumprir sua função, em fevereiro de 1936, a Comissão de Repressão elaborou uma lista de nomes destinados à prisão, tais como: o prefeito do Distrito Federal Pedro Ernesto Batista, o jornalista Maurício de Lacerda, o educador e signatário do Manifesto dos Pioneiros, Anísio Teixeira, entre muitos.

Em setembro do mesmo ano, foi instituído o Tribunal de Segurança Nacional - que funcionou até 1945. Em seus bancos ocuparam réus tanto da esquerda brasileira como também políticos liberais e integralistas. Ou seja, qualquer um que pudesse ser apontado como adversário da extensão do mandato de Getúlio Vargas corria o risco de ser acusado como elemento perigoso à ordem vigente.

\section{A perseguição dos intelectuais}

O clima de perseguição obstinada ao "comunismo" e aos intelectuais não alinhados à política de Vargas e/ou à Igreja Católica continuou. Incluíam-se ainda no processo persecutório quem ousasse pensar diferente, como por exemplo os professores Anísio Teixeira, Cecília Meireles e José Oiticica. Na esteira da repressão, houve a demissão e prisão do prefeito do Distrito Federal, Pedro Ernesto, assumindo o cargo, de forma 
interina, o presidente da Câmara dos vereadores, cônego Olimpio de Mello (03/04/1936 a 02/07/1937).

Como prefeito, cônego Olimpio assinou a demissão de vários "adversários" do regime ou suspeitos de ligações com o comunismo. Perderam seus cargos os intelectuais Edgar Süssekind de Mendonça (marido de Armanda) e Anísio Teixeira, ambos professores do Instituto de Educação.

A apresentação dos fatos ilustra a efervescência política dessa década e a importância do papel dos intelectuais na cena pública do país, expondo ideias, escrevendo, manifestando-se através de discursos e conferências, engajando-se em atividades de oposição ao governo e à Igreja Católica.

Como parte do processo de repressão, Armanda Álvaro Alberto foi presa em 8 de outubro de 1936, ficando detida na Casa de Detenção até 22 de junho de 1937. Sua prisão deu-se "por motivos políticos", como esclarece a ata de 21 de outubro de 1937 da Assembleia Geral de Sócios da Fundação Álvaro Alberto - instituição que administrava a Escola Regional de Meriti. De 4 de dezembro de 1935 a 22 de dezembro de 1936, também esteve preso seu companheiro Edgar Süssekind de Mendonça por motivo idêntico ao da educadora.

Em companhia de Armanda Álvaro Alberto estavam Olga Benário Prestes (Maria Gergner Prestes ou Maria Benário, extraditada grávida para a Alemanha e morta em um campo de concentração) ${ }^{6}$, Maria Moraes Werneck de Castro (participante da comissão jurídica e de organização da UFB), Auguste Elise Ewert (ou Machla Berger) Carmen Alfaia de Ghioldi, Júlia dos Santos, Eneida Costa de Moraes, Valentina Leite Barbosa Bastos e Eugênia Álvaro Moreira (O IMPARCIAL, 1\%12/1936).

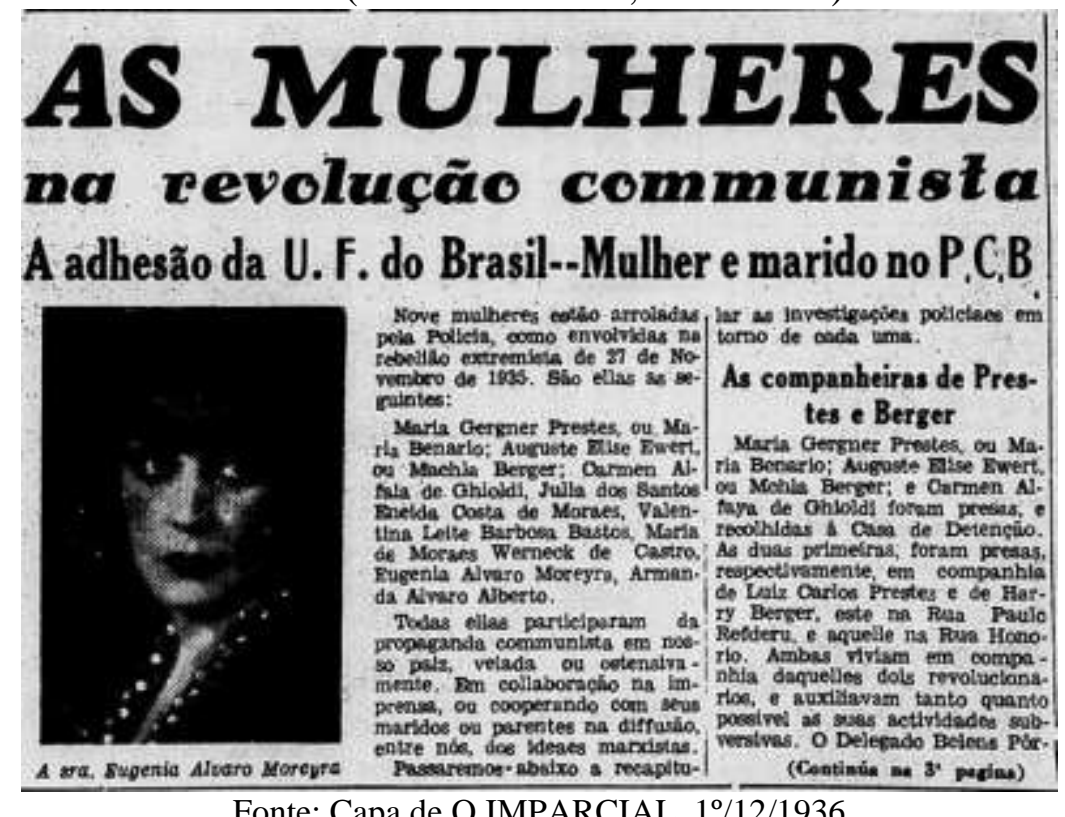

Fonte: Capa de O IMPARCIAL, $1 \% / 12 / 1936$

A prisão de Armanda estava enquadrada no artigo $1^{\circ}$ da Lei $\mathrm{n}^{\circ} 38$ combinado com o artigo $20^{\circ}$ em que acusavam a professora de "pertencer a UFB, entidade que prestou auxílio à ANL por intermédio de Maria Werneck Castro. Os artigos em questão definiam:

Artigo $1^{\mathrm{o}}$ Tentar diretamente e por fato, mudar, por meio violento, a Constituição da República, no todo ou em parte, ou a forma de governo 
por ela estabelecida. Pena - Reclusão de 6 a 10 anos aos cabeças e por 5 a 8 anos aos corréus.

[...]

Artigo $20^{\circ}$ Promover, organizar ou dirigir sociedade de qualquer espécie, cuja atividade se exerça no sentido de subverter ou modificar a ordem polícia ou social por meios não consentidos em lei. Pena - de 6 meses a 2 anos de prisão celular. $\S 1^{\circ}$ Tais sociedades serão dissolvidas e seus membros impedidos de se reunir para os mesmos fins. (LEI $n^{\circ} 38 \mathrm{de}$ 4/4/1935).

Em 16 de março de 1937 reuniu-se o Tribunal de Segurança Nacional para ouvir as testemunhas de acusação e as de defesas. A manchete do jornal O Globo acusavam as mulheres presas e exigia punição ao publicar "Eva no Tribunal de Segurança". Tal publicação esperava a condenação das mulheres desobedientes assim como no Gênese bíblico. O advogado de Armanda, Edmundo Miranda Jordão, dispensou a presença de testemunhas. Posteriormente juntou ao processo cartas de Roquete Pinto, Gustavo Lessa e Belisário Pena que conheciam a professora e atestavam sua conduta íntegra na sociedade

Após a substituição do ministro interino da Justiça Argamenon Magalhães por José Carlos de Macedo Soares ocorreu a libertação de 408 presos políticos sem processo formado que estavam envolvidos no movimento de 1935. Atitude criticada pelos conservadores, principalmente alguns católicos que expressavam a condenação divina do procedimento.

Armanda estava finalmente livre e, em 28 de julho de 1937, por maioria dos votos do Tribunal as mulheres que foram presas consideradas isentas de culpa.

Depois deste episódio Armanda Alberto se dedicou apenas à administração da Escola Regional de Meriti. Ainda que na ata de 1939 indique que a professora estava afastada por determinação política e sua mãe a substituía como presidente da Fundação Álvaro Alberto.

\section{Considerações finais}

Ao estudarmos esse período brasileiro e identificarmos nele a trajetória de Armanda Álvaro Alberto, percebemos o quanto sua atuação foi inovadora. Como uma intelectual assumiu os riscos de uma militância tanto em torno do pensamento escolanovista como na luta dos direitos das mulheres e das crianças. Sua ações não se limitaram a imitar modelos "importados", mas a criar práticas que fossem adequadas às realidades brasileiras, mais especificamente em Meriti.

Com uma proposta de educação regional, Armanda procurou concretizar uma experiência de Escola Nova com um projeto inovador no campo educacional brasileiro. Além da biblioteca, dos passeios, do círculo de mães, concursos voltados para a população vizinha da escola, também ofereceu merenda para as crianças. Essa ação rendeu o nome carinhoso para a escola de "Mate com angu".

Sem dúvida, a Escola Regional foi um local que Armanda Alberto procurou concretizar uma experiência de Escola Nova no Brasil. Entretanto, a instituição que reconhecidamente sustentava-se em bases escolanovistas também carregava contradições dentro de uma localidade pobre e desamparada do poder público onde tudo estava por se fazer em termo de educação. Para Armanda a escola deveria contribuir para a permanência de homens e mulheres na comunidade atendida e evitar sua saída do campo. Assim, trazia 
em seu interior uma espécie de conformação social sem procurar desestabilizar o núcleo da dominação sócio-político-econômico.

Em uma conjuntura de embates e disputas no Brasil, juntamente com o acirramento ideológico, Armanda Álvaro tomou posição e manifestou-se contra o imperialismo e o integralismo. Assim, ao defender os direitos das mulheres e lutando por uma nova sociedade afrontou os preconceitos da época sendo nomeada de "Eva", ou seja, a traidora da humanidade. Ao manifestar sua contrariedade com a situação brasileira foi vigiada, perseguida e presa, assim como outros intelectuais do período. Podemos concluir que em sua trajetória de educadora e militante feminista Armanda manteve a coerência de acreditar na possibilidade de uma sociedade nova e de uma educação que atendesse a população afastada dos grande centros.

\section{Referências}

ALBERTO, Armanda Álvaro. A cultura popular na Escola Regional de Meriti. Mimeo. 1932B.

ALBERTO, Armanda Álvaro. A escola regional de Meriti. Rio de Janeiro: INEP-MEC, 1968.

Alberto, Armanda Álvaro. Como iniciei a Escola Regional na Ponta da cidade em Angra dos Reis - continuada em Merity. Mimeo. 1932A.

ALIANÇA NACIONAL LIBERTADORA. Estatuto. 1935. Rio de Janeiro, 21 de março de 1935.

ALMEIDA, Julia Lopes. Um maço de cartas. In: ALBERTO, Armanda Álvaro. A escola regional de Meriti. Rio de Janeiro: INEP-MEC, 1968.

AZEVEDO, Fernando de. A cultura Brasileira. $6^{\text {a }}$ ed. Rio de Janeiro: Editora UFRJ: Editora UnB, 1996.

BRASIL. Decreto no 229. 11 de julho de 1935.

BRASIL. Decreto no 246. 19 de julho de 1935.

BRASIL. Lei $\mathbf{n}^{\mathbf{0}}$ 38, Lei de Segurança Nacional. 4 de abril de 1935.

DOSSIÊ 5 - UFB. Setor Comunismo. Delegacia Especial de Segurança Política e Social (DESPS). S/D.

JEAN, Yvonne. Inovações admiráveis. In: ALBERTO, Armanda Álvaro. A escola regional de Meriti. Rio de Janeiro: INEP-MEC, 1968.

KELLER, Vilma. Vicente Rao. Verbete In: ABREU, A. A., BELOCH, I.; LATTMANWELTMAN, F.; LAMARÃO, S. T. N. (Coord.). Dicionário Histórico Biográfico Brasileiro pós 1930. Rio de Janeiro: Editora FGV, 2001. 5 vol.

LOURENÇO FILHO, Manuel Bergström. Introdução ao estudo da escola nova. $12^{\mathrm{a}}$ ed. São Paulo: Melhoramentos; Rio de Janeiro: Fundação nacional de material escolar, 1978.

MENDONÇA, Edgar Süssekind de. A Escola Regional de Meriti (realizações e projetos). In: ALBERTO, Armanda Álvaro. A escola regional de Meriti. Rio de Janeiro: INEPMEC, 1968. 
MIGNOT, A. C. V. Baú de memórias, bastidores de histórias: o legado de Armanda Álvaro Alberto. Bragança Paulista, SP: EDUSF, 2002.

OSÓRIO, Beatriz. Escola Regional de Merity. Monografia. Mimeo. Rio e Janeiro, 1944.

RELATÓRIO Sobre Atividades Comunistas n ${ }^{\circ} 1$ [muito reservado]. Setor Comunismo. Delegacia Especial de Segurança Política e Social (DESPS). 5 de julho de 1944.

UNIÃO FEMININA DO BRASIL. Manifesto Programa. 1935.

VENÂNCIO FILHO, Alberto (org). Francisco Venâncio Filho: um educador brasileiro. Rio de Janeiro: Nova Fronteira, 1994.

VENÂNCIO FILHO, Alberto. Francisco Venâncio Filho e o movimento euclidiano. Rio de Janeiro, 1989.

VIANNA, Marly (org). Pão, terra e liberdade: memória do movimento comunista de 1935. Rio de Janeiro: Arquivo Nacional; São Carlos: UFSCar, 1995.

\section{Arquivos}

Arquivo e Biblioteca do Conselho Nacional de Educação (CNE) - Brasília - DF

Arquivo Edgar Leuenroth - AEL/IFCH - UNICAMP - Campinas - SP

Arquivo Nacional - Rio de Janeiro

Arquivo Público do Estado do Rio de Janeiro - APERJ - Rio de Janeiro

Programa de Estudos e Documentação Educação e Sociedade - PROEDES - UFRJ - Rio de Janeiro

Supremo Tribunal de Justiça -STJ - Brasília - DF

Notas

${ }^{1}$ Professor do Programa de Pós-Graduação em Educação da Universidade Federal do Estado do Rio de Janeiro (UNIRIO). Doutor em Educação pela Universidade Estadual de Campinas (Unicamp). Membro do Núcleo de Estudos e Pesquisas em História da Educação Brasileira. Email: jdamiro@ gmail.com

${ }^{2}$ Um detalhe é que Armanda Álvaro Alberto não menciona que essa fábrica pertencia ao seu irmão.

${ }^{3} \mathrm{Na}$ época, situada no município de Nova Iguaçu, estação Meriti da estada de ferro Leopoldina. Depois o município recebeu o nome de Duque de Caxias. E a estação transformou-se na cidade de Meriti, localizada na Baixada Fluminense.

${ }^{4}$ Essa homenagem originou-se no Grêmio Literário Euclides da Cunha, criado em 1910 pelos irmãos Carlos e Edgar Süssekind de Mendonça no Internato Nacional Bernardo Vasconcelos (depois Pedro II). A iniciativa continuou na residência dos Süssekind de Mendonça. Participaram dessa homenagem Francisco Venâncio Filho, Álvaro Alberto (irmão de Armanda), Rui Castro, Roberto Lira, Maurício Joppert, entre outros (Cf. VENÂNCIO FILHO, 1994; 1989).

${ }^{5}$ Vicente Paulo Francisco Rao (1892-1978) - Ministro da Justiça e Negócios Interiores no governo Getulio Vargas, empossado em 1934. Neste mesmo ano participou da fundação da USP; foi o responsável pela da Lei de Segurança Nacional, em 1935 e pelo fechamento da ANL; em 1936, criou a Comissão Nacional de Repressão ao Comunismo; pediu exoneração do Ministério em janeiro de 1937 em solidariedade à Armando Sales que renunciara ao cargo de governador de São Paulo para disputar as eleições para a Presidência da República. Após este fato, volta à atividade de advogado e de professor na Faculdade de Direito da USP; 
com o Estado Novo foi demitido do cargo de professor, retornando à função em 1941 (KELLER, 2001, p. 4899-4902).

${ }^{6}$ O governo de Getúlio Vargas, para fugir de qualquer acusação "humanitária" noticiou que Olga havia abortado; mesmo assim, o Socorro Vermelho Internacional, grupo de apoio ao presos políticos, denunciou que isso havia se dado pelas torturas que essa militante comunista havia sofrido. Posteriormente soube-se que ela teve sua filha, procurada e encontrada pela família Prestes

Recebido em setembro-13

Aprovado em novembro-13 